\title{
Model-based design of smart active packaging systems with antimicrobial activity
}

\author{
Carlos Vilas ${ }^{\mathrm{a}}$, Miguel Mauricio-Iglesias ${ }^{\mathrm{b}}$, Míriam R. García ${ }^{\mathrm{a}, *}$ \\ ${ }^{a}$ (Bio)Process Engineering Group, IIM-CSIC, r/ Eduardo Cabello, 6, 36208, Vigo (Spain) \\ ${ }^{b}$ Department of Chemical Engineering, School of Engineering, Universidade de Santiago de \\ Compostela, r/ Lope Gómez de Marzoa, E-15782 Santiago de Compostela (Spain)
}

\begin{abstract}
Smart active packaging is an innovative packaging system that combines the benefits of measuring, estimating or predicting different aspects of food quality or safety with the release of an active substance that extends product shelf life. Nevertheless, in its typical configuration, the active packaging and the smart packaging are not connected, and the information provided is not exploited to design the release of the active substance.

In this work, we demonstrate how smart active packaging systems using predictive mathematical models allow the automatic optimisation of food packaging design and the prediction of the expected shelf life along the food chain. On the one hand, the system calculates the best design of the active packaging and the concentration of the active substance in the different layers that maximise food quality and safety. On the other hand, the model allows to calculate and update shelf life values along the food chain under unexpected changes in the storage conditions. Shelf life estimations and prediction will help distributors and sellers to adjust the product market prices. For example, prices can be lowered to avoid food losses when the product is close to its use-by date.

Hake (Merluccius merluccius) represents an example of a highly relevant and perishable food that can be conserved using natural antimicrobials. Therefore, the case study selected to illustrate the proposed methodology consists of the
\end{abstract}

\footnotetext{
* Corresponding author

Email address: miriamr@iim.csic.es (Míriam R. García)
} 
smart active packaging of hake using carvacrol as the active substance (antimicrobial). Besides, different polymers are considered as possible active packaging materials. The Matlab ${ }^{T M}$ codes required to perform the simulations of the models described in this work as well as the optimisations for packaging design are available at https://doi.org/10.5281/zenodo.3244153.

Keywords: Smart active packaging, Model-based optimal design, Predictive Microbiology, Shelf life, Antimicrobial activity, Fish freshness

\section{Introduction}

Smart active packaging is an innovative packaging system that combines the benefits of measuring, estimating or predicting different aspects of food quality or safety (Yam et al., 2005, García et al., 2017) with the release of

5 an active substance that extends product shelf life (Wyrwa \& Barska, 2017). This innovative packaging system responds to current consumer's preferences for minimum processing foods of high quality, while allowing distributors and sellers to avoid food wastage by adjusting market prices based on reliable information about product shelf life (Zhang et al., 2015, García et al., 2015). The smart active packaging is a crucial element for an emerging food industry 4.0 with adaptive production and intelligent tracking systems.

The combination of smart and active packaging solutions originates from the need to develop a general approach that permits to predict food product shelf life and to exploit this information to design the release of the active substance. Nevertheless, and despite a large number of works demonstrating the benefits of innovative packaging systems, this general approach is still missing (Guillard et al., 2018). The main problem is that, although smart packaging alone is able to provide information on current food state, using either direct or indirect measurements (Pacquit et al., 2007; Giannoglou et al., 2014), it does not provide estimations or the influence of factors such us package design or storage conditions on expected product shelf life.

Shelf life predictions require the harmonisation of two different types of dy- 
namic quantitative models in smart active packaging: (1) one model describing the release of the active substance and (2) another model describing shelf life in terms of food safety and quality. Shelf life predictions are critical to optimally design aspects such as the selection of the multilayer packaging material, the robustness of the chosen design to variable storage conditions or the initial concentration of the active agent. Recently developed predictive tools for enhanced packaging have focused on the simulation of modified atmosphere packaging (Chaix et al. 2015; Antunes-Rohling et al., 2019). The development of a whole framework to assist in packaging and product design is required to boost the use and confidence of the food industry in these novel solutions, and in particular, in active packaging.

There is an established and reliable theory for mathematically describing the release of the active agent in active packaging. Such release from a polymeric packaging material is, in general, governed by three parameters: the diffusivity in the packaging $\left(D_{i}\right)$, the partition coefficient $\left(K_{p f}\right)$ describing the affinity for the active agent between the food product and the packaging, and the mass transfer coefficient $\left(k_{L}\right)$ or the diffusivity in the food product, for liquid-like 40 or solid foodstuff respectively (Martinez-Lopez et al. 2015). In most cases, diffusion in the packaging and partition between compartments are the limiting steps and therefore the most crucial parameters needed for simulation, although additional information is required when deviations from Fickian diffusion are relevant as in the case of polymer swelling (Mauricio-Iglesias et al., 2009). As

45 a conclusion, the biggest challenge in simulating the active agent release is the availability of the relevant parameters $\left(D_{i}\right.$ and $\left.K_{p f}\right)$ given that the mathematical description and solution are well-established.

More challenging is the modelling of food shelf life: a complex and dynamic concept that combines different food safety and quality aspects, including sub50 jective or cultural organoleptic preferences. Shelf life is a dynamic estimation of the time span where the product is in good conditions for consumption and depends on multiple factors such as storage temperature (Jedermann et al., 2014). In general terms, shelf life is defined to guarantee food safety ("use-by" date), 
or to ensure both safety and quality food standards ("best-before" date).

Good predictive shelf life models are product specific and are especially advantageous for highly perishable foods such as fresh shellfish and fish meat (Cerisuelo et al. 2013). Among them, the value of hake (Merluccius merluccius) landed in the $\mathrm{EU}$ is the highest, accounting for 470 million $€$ (roughly $7 \%$ of the total) in 2015 EUMOFA (2017). Carvacrol, the principal antimicrobial agent in oregano essential oil, has been reported as one of the most active natural antimicrobial compounds inducing permeability alteration in cell membranes resulting in cell death (Ben Arfa et al. 2006). As a result, it has been used as a standard option to extend fish shelf life, including hake (Otero-Tuárez et al. 2019).

A critical safety index both in fresh and cooked seafood products is the growth of Listeria monocytogenes. One of the first documented outbreaks with death casualties linking L. monocytogenes with the consumption of shellfish and raw fish dates from 1980 (Dillon \& Patel, 1992). L. monocytogenes may survive cooking and growth at refrigeration temperatures and affects widely consumed products such as cold-smoked salmon, frozen canned cooked crab meat and surimi products among others (Benabbou et al., 2018; Dillon \& Patel, 1992).

Fish quality, usually associated with freshness, does not only relate to safety. It is a complex attribute that depends on both microbial and biochemical changes as well as cultural and personal preferences. Spoilage microorgan75 isms commonly degrading quality in fish muscles at low temperature are (psychrotrophic) Pseudomonas and Shewanella (Gram \& Dalgaard, 2002). Biochemical changes may be detected using different measurements such as the total volatile base-nitrogen generated (TVB-N) or thrimethylamine (TMA). Conventional detection of early changes in quality attributed is determined using the ${ }_{80} K_{I^{-}}$-value for fresh and frozen fish (Saito et al., 1959, Karube et al., 1984, Hong et al. 2017, Li et al. 2019). This index relates the concentration of Inosine monophosphate (IMP), Inosine (Ino) and Hypoxanthine (Hx) in fish muscle. IMP is related to the umami taste of fish whereas its degradation and the formation of $\mathrm{Hx}$ is connected to unpleasant bitterness. Recently, Vilas et al. 
(2018) showed that spoilage bacteria accelerate the degradation of IMP into Ino and Hx. The authors derived a mathematical model describing the degradation of IMP, including the effect of spoilage bacteria (Pseudomonas spp. and Shewanella spp.) as well as leaching of nucleotides. Under active packaging, the antimicrobial agent limits spoilage bacterial growth, thus delaying quality degradation.

In this work, we present a procedure for the integral design of smart active packaging systems by using mathematical models to: (1) optimally design the packaging/food system for a given objective and (2) assess and predict shelf life taking into account changes on the food chain conditions. To the authors knowledge, this work is the first one providing a mathematical model that describes the evolution of quality and safety indicators in a system comprising both active packaging and food product. The contribution also provides modelbased tools and formulations for systematic design, food chain assessment, and shelf-life estimations. We demonstrate our approach by designing a smart active packaging of hake fillets, with increased shelf life thanks to the steady release of the antimicrobial carvacrol. In this regard, we consider different polymers as active packaging materials and select the optimal configuration of the multilayer packaging material, including the thickness of each layer. We also provide the optimal concentration of carvacrol in each layer. Robustness of the chosen design is tested by considering variable storage conditions, including temperature abuses and changes of the time span between packaging manufacturing and food-packaging contact.

\section{Materials and Methods}

\subsection{Smart active packaging description}

The active packaging/food product selected in this work represents a packed foodstuff that is modelled as a multi-compartment system composed by several film layers wrapping the food product as described in Figure 1. At $t=0$, the active compound, carvacrol, is only present in the packaging, and it is transferred 
to lower concentration regions both in the food and in the different layers of packaging. Likewise, at $t=0$, a certain initial microbial load is assumed in the surface of the fish fillet. The evolution of the microbial load depends on the temperature and on the concentration of carvacrol in the fillet surface.

Seeking a trade-off between model fidelity and simplicity of use, the following assumptions were considered in model derivation:

- Transfer rate of carvacrol is well described by 1-D transfer in the thickness dimension as the packaging thickness is much smaller than its length or width.

- No carvacrol is transferred to the outer environment due to carvacrol's low volatility, although flux conditions can be used to simulate more volatile active compounds.

- Inner packaging layer is in good contact with the food product and resistance to transfer is low, which is a suitable approximation for solid/solid interfaces. Note, in any case, that the model formulation allows situations such as imperfect contact which can be modelled as an increased mass transfer resistance (Roca et al. 2008).

- Temperature is homogeneous in both the packaging and the fillet surface and it is equal to environmental temperature at all times. Note that heat transfer is considerably faster than mass transfer both in packaging and food (Lewis number $>>1$ ).

- Bacteria are initially located on the fillet surface, which might have been contaminated during the cutting process (Proctor \& Nickerson, 1935). Also, bacterial migration to the food matrix interior is much slower than carvacrol diffusion. In consequence, quality and safety issues are more relevant on the surface. Therefore, modelling bacterial and carvacrol distribution inside the food matrix is not required.

It should be noted that some parts of the presented model, namely bacterial growth and nucleotide degradation, have been validated in previous works 
(García et al., 2015, Vilas et al. 2018). The diffusion of carvacrol in polymers is expected to be well described by Fickian kinetics. On the other hand, the effect of carvacrol on the bacteria would require a case-by-case experimental validation before implementation into a specific industrial application.

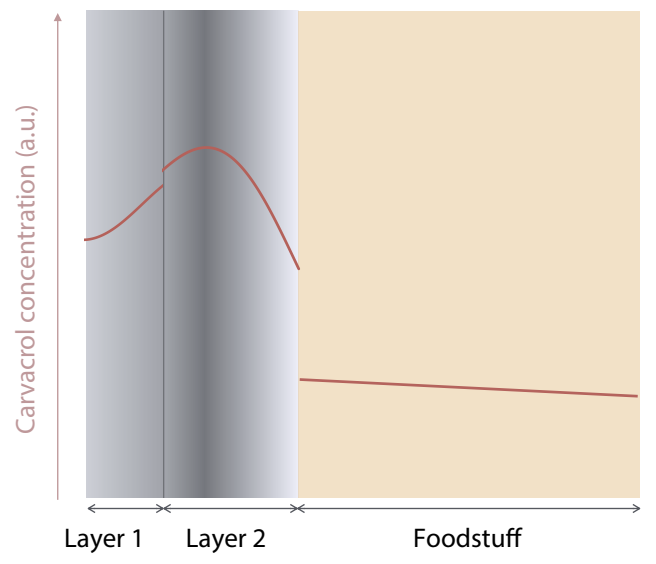

Figure 1: Diagram of the packaging/food system illustrating a bilayer packaging material and the food product with varying carvacrol concentration (red line) in the direction of the packaging thickness. Quasi-homogeneous carvacrol concentration is expected in the foodstuff as mass transfer limitation takes place in the packaging compartment(s).

\subsubsection{Prediction of active substance release}

Mass transfer across polymeric food packaging takes place mainly by diffusion. Therefore, we use Fick's law, with diffusivity term independent of solute concentration (Mauricio-Iglesias et al., 2009), in combination with a mass balance to describe the evolution and distribution of carvacrol in the packaging:

$$
\frac{\partial C_{i}}{\partial t}=D_{i} \frac{\partial^{2} C_{i}}{\partial x^{2}} ; \quad \text { with } i=1,2, \ldots, n ; \quad t>0 ; \text { and } \quad x_{i-1}<x<x_{i}
$$

where $C_{i}(t, x)\left(\mathrm{kg} / \mathrm{m}^{3}\right)$ and $D_{i}(T)\left(\mathrm{m}^{2} / \mathrm{s}\right)$ are, respectively, the concentration of carvacrol and its diffusivity in layer $i . x$ is the distance to the environment. Layer $i$ is defined between spatial coordinates $x_{i-1}$ and $x_{i}$, where $x_{0}=0$ and $x_{n}=H$. In order to solve Eq (1) initial and boundary conditions must be 
defined. Initial carvacrol concentration in each of the layers is defined as:

$$
\begin{array}{cc}
C_{1}\left(t_{0}, x\right)=C_{1,0}(x) ; & 0 \leq x \leq x_{1} \\
C_{2}\left(t_{0}, x\right)=C_{2,0}(x) ; & x_{1} \leq x \leq x_{2}
\end{array}
$$

$$
C_{n}\left(t_{0}, x\right)=C_{n, 0}(x) ; \quad x_{2} \leq x \leq H
$$

The active packaging has three types of boundaries: the outer environment, interface between films and the food matrix. As mentioned above, no flux of carvacrol is considered between the active packaging and outer environment. Mathematically, this is formulated as:

$$
\left.\frac{\partial C_{1}}{\partial x}\right|_{x=0}=0 .
$$

Contact between films in multilayer is considered as perfect and, at the interface, the equilibrium condition holds. Hence, between layers $i$ and $i+1$, boundary condition is written as:

$$
\left.C_{i}\right|_{x_{i}^{-}}=\frac{\left.C_{i+1}\right|_{x_{i}^{+}}}{K_{i, i+1}}
$$

with $K_{i, i+1}$ being the partition coefficient. Flux of carvacrol between the active packaging and the food matrix is described by:

$$
\left.D_{n} \frac{\partial C_{n}}{\partial x}\right|_{x=H}=k_{L}\left(K_{p f} C_{f}-\left.C_{n}\right|_{x=H}\right) .
$$

where $K_{p f}$ is the partition coefficient between the packaging and the product, and $k_{L}(\mathrm{~m} / \mathrm{s})$ is the mass transfer coefficient in the packaging/food interface. The concentration of carvacrol in the fillet surface $\left(C_{f}\right)$ is determined by a mass balance:

$$
\frac{d C_{f}}{d t}=-k_{L} a\left(K_{p f} C_{f}-\left.C_{n}\right|_{x=H}\right),
$$

where $a$ is the specific exchange area defined as:

$$
a=\frac{A}{V_{L}}=\frac{\text { exchange area }}{\text { liquid volume }} .
$$

175

Initial conditions for Eq (5) are of the form:

$$
C_{f}\left(t_{0}\right)=C_{0}
$$


Diffusivity changes with temperature are modelled by an Arrhenius-like dependence:

$$
D_{i}(T)=D_{i}\left(T_{r e f}\right) \exp \left(-\frac{E_{A, i}}{R}\left(\frac{1}{T}-\frac{1}{T_{r e f}}\right)\right)
$$

where $E_{A}$ is the activation energy, $R$ is the ideal gas constant and $T$ is the temperature. Model parameters are summarised in Table 1. Some of the parameters in the table were obtained by combining the values provided in several references. The reader is referred to Appendix A for details on such derivation.

Table 1: Mass transfer parameters for carvacrol in the different layers: polypropylene (PP); low-density polyethylene (LDPE); high-density polyethylene (HDPE).

\begin{tabular}{|c|c|c|c|c|c|}
\hline Parameter & Value & Units & \multicolumn{3}{|l|}{ References } \\
\hline$T_{\text {ref }}$ & 293 & $\mathrm{~K}$ & \multicolumn{3}{|l|}{-} \\
\hline$D_{P P}\left(T_{r e f}\right)$ & $1.77 \times 10^{-15}$ & $\mathrm{~m}^{2} \mathrm{~s}^{-1}$ & Cerisuelo et al. 2012 & Krepker et al. & 2018) \\
\hline$D_{L D P E}\left(T_{r e f}\right)$ & $8.10 \times 10^{-14}$ & $\mathrm{~m}^{2} \mathrm{~s}^{-1}$ & \multicolumn{3}{|l|}{ Rupika, 2010) } \\
\hline$D_{H D P E}\left(T_{r e f}\right)$ & $1.8 \times 10^{-17}$ & $\mathrm{~m}^{2} \mathrm{~s}^{-1}$ & \multicolumn{3}{|l|}{ Peltzer et al. 2009) } \\
\hline$E_{A, P P}$ & $1.27 \times 10^{5}$ & $\mathrm{~J} \mathrm{~mol}^{-1}$ & \multicolumn{3}{|c|}{ (Cerisuelo et al. 2012: Krepker et al. 2018) } \\
\hline$E_{A, L D P E}$ & $1.01 \times 10^{5}$ & $\mathrm{~J} \mathrm{~mol}^{-1}$ & \multicolumn{3}{|l|}{ Rupika, 2010) } \\
\hline$E_{A, H D P E}$ & $2.14 \times 10^{5}$ & $\mathrm{~J} \mathrm{~mol}^{-1}$ & \multicolumn{3}{|l|}{ (Peltzer et al. 2009) } \\
\hline$K_{p f}$ & 124 & $\frac{m^{3} \text { food }}{m^{3} P P}$ & \multicolumn{3}{|c|}{ (Cerisuelo et al. 2012, 2013) } \\
\hline$k_{L}$ & $5.0 \times 10^{-3}$ & $\mathrm{~ms}^{-1}$ & \multicolumn{3}{|c|}{ (Martinez-Lopez et al. 2015) } \\
\hline$a$ & 60 & $\mathrm{~m}^{-1}$ & (EU Commission, 2004 & & \\
\hline$R$ & 8.314 & $\mathrm{~J} \mathrm{~mol}^{-1} \mathrm{~K}^{-1}$ & \multicolumn{3}{|l|}{ 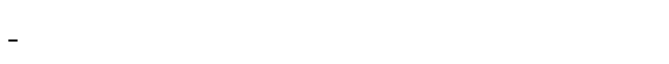 } \\
\hline
\end{tabular}

Regarding partition coefficients in boundary condition (3), it is likely that carvacrol partitions in a similar way between LDPE, HDPE and PP, given that these polymers are chemically similar. Therefore, in multilayer configurations we consider $K_{1,2}=K_{2,3}=1$, although other values could be easily implemented. 


\subsubsection{Prediction of shelf life}

Shelf life is a dynamic estimation of the use-by date (based on food safety) or the best-before date (considering both food safety and quality arguments). For retail fish fillets, these indexes are based on relevant biochemical and microbial dynamics. Freshness at early storage times is mainly related to IMP biochemical degradation compounds which, as shown in Saito et al. (1959); Hong et al. (2017), can be combined to define a freshness indicator, the $K_{I}$ index. Microbial dynamics incorporates the changes of pathogens affecting food safety and spoilers degrading food quality.

Based on predictive microbiology theory, microbial dynamics of pathogens and spoilers are described using primary, secondary or tertiary models. Tertiary models consist of the combination of primary and secondary models with userfriendly platforms to make them accessible to non-experts. Tertiary models are out of the scope of this work. Regarding primary and secondary models we will consider, using the Occam's razor principle, the simplest description able to capture main relevant features.

Primary models describe the growth dynamics of the microbial population. Baranyi \& Roberts (1994) proposed the standard for a primary model that, in the mathematical form described in García et al. (2015), reads:

$$
\frac{\mathrm{d} y}{\mathrm{~d} t}=\mu\left(1-10^{y-y^{*}}\right)
$$

where $y$ represents the logarithm colony-forming units per gram $(\mathrm{CFU} / \mathrm{g})$ in a population. Assuming that one viable cell forms one colony, this state represents the concentration of viable cells in a population in logarithmic scale. The model describes two phases: exponential growth with velocity $\mu$ and a stationary phase with the maximum density of viable cells represented by $y^{*}$. No lag phase is considered as microorganisms are assumed to be fully adapted and lag phase models are highly uncertain. This approach is the most conservative, and safest one. This is a well-established assumption EFSA (European Food Safety Authority), 2015).

Secondary models define how parameters in primary model, in particular 
els describe the dependence of the growth rate with temperature $(T)$ and carvacrol concentration $\left(C_{f}\right)$ following the multiplicative model Augustin \& Carlier, 2000b):

$$
\mu=\mu^{*} \gamma_{T} \gamma_{C}
$$

where $\mu^{*}$ is the maximum growth rate and $\gamma_{T}$ and $\gamma_{C}$ are functions, ranging 220 from the optimal one and due to carvacrol presence, respectively. The particular form of $\gamma_{C}$ and $\gamma_{T}$ is presented in Eqns. (9) and (10).

Secondary models of inhibition by temperature $\left(\gamma_{T}\right)$ are well-known and diverse. The selection of a particular model among the different choices depends 225 on the bacterial strain and the range of interest in the experiment. For this reason, they will be defined for each of the bacterial strains considered.

Secondary models of antimicrobial effect, nevertheless, are scarce and very limited (García \& Cabo, 2018). For this work we will use the simplest model, and probably the most common, which only requires a value for the Minimum Inhibitory Concentration (MIC):

$$
\gamma_{C}= \begin{cases}\left(1-\frac{C_{f}}{M I C}\right)^{2}, & C_{f}<M I C \\ 0 & C_{f} \geq M I C\end{cases}
$$

This model is named the square root model (Dalgaard, 1995) and will be used for both pathogens and spoilers. As mentioned above, case-by-case experimental validation would be required before model implementation into a specific industrial application.

Reference index for food safety. The objective is to develop the simplest model of Listeria inhibition by carvacrol at non-isothermal conditions. We should stress that the limits established by EFSA (the European Food Safety Authority) for Listeria monocytogenes are low and the stationary phase can be omitted from the primary model (7). 

studied. Most works use the cardinal temperature model (see Rosso et al. (1995) for details):

$$
\gamma_{T}= \begin{cases}f(T), & T_{-} \leq T \leq T_{+} \\ 0 & T_{-}>T \text { or } T_{+}<T\end{cases}
$$

with

$$
f(T)=\frac{\left(T-T_{-}\right)\left(T-T_{-}\right)^{2}}{\left(T_{*}-T_{-}\right)\left[\left(T_{*}-T_{-}\right)\left(T-T_{*}\right)-\left(T_{*}-T_{+}\right)\left(T_{*}+T_{-}-2 T\right)\right]}
$$

where $T_{*}$ is the temperature at which the growth rate is maximum and $T_{-}$and $T_{+}$are, respectively, the temperatures below which and above which no growth occurs. In other words, $T_{-}$and $T_{+}$determine the range of growth.

Model for Listeria monocytogenes (Lm), with $\gamma$ functions defined in 10 for $\gamma_{T}$ and in (9) for $\gamma_{C}$, reads as:

$$
\frac{\mathrm{d} \log _{10} \mathrm{Lm}}{\mathrm{d} t}=\mu^{*} \gamma_{T} \gamma_{C}\left(1-10^{\log _{10} \mathrm{Lm}-\log _{10} \mathrm{Lm}^{*}}\right)
$$

As mentioned above, limits established by EFSA are low, i.e. $\mathrm{Lm} \ll \mathrm{Lm}^{*}$, so Eq. (11) can be approximated by:

$$
\frac{\mathrm{d} \log _{10} \mathrm{Lm}}{\mathrm{d} t}=\mu^{*} \gamma_{T} \gamma_{C}
$$

Table 2 shows the parameters of the operational predictive microbial model of Listeria monocytogenes inhibition with carvacrol.

Reference index for food quality. We have selected the $K_{I}$-index as the parameter determining early changes in food quality since it is a widely accepted indicator. $K_{I}$-index is defined as (Hong et al., 2017):

$$
K_{I}(\%)=\frac{\mathrm{Ino}+\mathrm{Hx}}{\mathrm{IMP}+\mathrm{Ino}+\mathrm{Hx}} 100
$$

The dynamic model describing IMP degradation has been derived in Vilas et al. (2018) and it integrates biochemical and microbiological changes. For the sake of completeness, let us summarise the model equations:

$$
\frac{\mathrm{dIMP}}{\mathrm{d} t}=-\left(k_{1}+k_{3}+k_{4}+k_{1, b a c}(\mathrm{Sh}+\mathrm{Ps})+D\right) \mathrm{IMP}
$$


Table 2: Parameter values defining the growth velocity of Listeria monocytogenes at non-isothermal conditions and under inhibition by carvacrol. The optimal growth $\mu^{*}$ corresponds with the estimations for fish.

\begin{tabular}{|c|c|c|c|c|c|}
\hline Parameter & Value & Units & \multicolumn{3}{|l|}{ References } \\
\hline$\mu^{*}$ & 1 & $\mathrm{~d}^{-1}$ & \multicolumn{2}{|c|}{ Augustin \& Carlier } & 2000a) \\
\hline$T_{-}$ & -2.7 & ${ }^{\circ} \mathrm{C}$ & Bajard et al. & 1996 & \\
\hline$T_{*}$ & 38.7 & ${ }^{\circ} \mathrm{C}$ & Bajard et al. & 1996 & \\
\hline$T_{+}$ & 42.3 & ${ }^{\circ} \mathrm{C}$ & Bajard et al. & 1996 & \\
\hline$M I C$ & 0.37 & $\mathrm{~kg} \mathrm{~m}^{-3}$ & Pol \& Smid & 1999 & \\
\hline
\end{tabular}

$$
\frac{\mathrm{dIno}}{\mathrm{d} t}=\left(k_{1}+k_{1, b a c}(\mathrm{Sh}+\mathrm{Ps})\right) \operatorname{IMP}-\left(k_{2}+k_{2, b a c}(\mathrm{Sh}+\mathrm{Ps})+D\right) \operatorname{Ino}
$$

260

$$
\frac{\mathrm{dHx}}{\mathrm{d} t}=k_{4} \mathrm{IMP}+\left(k_{2}+k_{2, b a c}(\mathrm{Sh}+\mathrm{Ps})\right) \operatorname{Ino}-D \mathrm{Hx}
$$

Reaction rate coefficients $k_{i}$ are described by Arrhenius expressions of the form:

$$
k_{i}=A_{i} \exp \left(-\frac{E_{a, i}}{R T}\right)
$$

with $T(\mathrm{~K})$ being the storage temperature. $k_{i, b a c}$ are constant parameters introduced in order to take into account the metabolic effect of spoilers, that is Pseudomonas spp. (Ps) and Shewanella spp. (Sh).

As shown in García et al. (2015), Bacterial growth of Pseudomonas spp. and Shewanella spp. in hake can be described by Eqn. (7) with the Ratkowsky model for temperature $\left(T-T_{P s}^{*}\right)^{2}$. The authors of the work validated the model using experimental data. In this work, we include a new term $\left(\gamma_{C}\right)$, see Eq (9), to take into account growth inhibition by carvacrol. Therefore, growth dynamics are described by:

$$
\frac{\mathrm{dPs}}{\mathrm{d} t}=\mu_{P s}^{*}\left(T-T_{P s}^{*}\right)^{2}\left(1-\frac{C_{f}}{M I C_{P s}}\right)^{2} \operatorname{Ps}\left(1-\frac{\mathrm{Ps}}{\mathrm{Ps}^{*}}\right)
$$




$$
\frac{\mathrm{dSh}}{\mathrm{d} t}=\mu_{S h}^{*}\left(T-T_{S h}^{*}\right)^{2}\left(1-\frac{C_{f}}{M I C_{S h}}\right)^{2} \mathrm{Sh}\left(1-\frac{\mathrm{Sh}}{\mathrm{Sh}^{*}}\right) .
$$

where, contrary to Eq (7), bacterial concentration is expressed in CFU/g. The values of the parameters in Eqs (14)- (19) are presented in Table 3.

Table 3: Parameter values used in the model describing food quality 14- 19 .

\begin{tabular}{|c|c|c|c|c|}
\hline Parameter & Value & Units & \multicolumn{2}{|l|}{ References } \\
\hline$E_{a, 1}$ & $1.16 \times 10^{5}$ & $\mathrm{~J} \mathrm{~mol}^{-1}$ & Vilas et al. 2017) & \\
\hline$A_{1}$ & $1.15 \times 10^{20}$ & $d^{-1}$ & Vilas et al. 2017) & \\
\hline$E_{a, 2}$ & $9.13 \times 10^{4}$ & $\mathrm{~J} \mathrm{~mol}^{-1}$ & Vilas et al. 2017) & \\
\hline$A_{2}$ & $7.63 \times 10^{15}$ & $d^{-1}$ & Vilas et al. 2017) & \\
\hline$E_{a, 3}$ & $1.07 \times 10^{5}$ & $\mathrm{~J} \mathrm{~mol}^{-1}$ & Vilas et al. 2017) & \\
\hline$A_{3}$ & $2.29 \times 10^{18}$ & $d^{-1}$ & Vilas et al. 2017) & \\
\hline$E_{a, 4}$ & $7.58 \times 10^{4}$ & $\mathrm{~J} \mathrm{~mol}^{-1}$ & Vilas et al. 2017) & \\
\hline$A_{4}$ & $4.84 \times 10^{12}$ & $\mathrm{~d}^{-1}$ & Vilas et al. 2017) & \\
\hline$k_{1, b a c}$ & $8.64 \times 10^{-8}$ & $\mathrm{~g} \mathrm{~d}^{-1} \mathrm{CFU}^{-1}$ & Vilas et al. 2018) & \\
\hline$k_{2, b a c}$ & $2.68 \times 10^{-7}$ & $\mathrm{~g} \mathrm{~d}^{-1} \mathrm{CFU}^{-1}$ & Vilas et al. 2018) & \\
\hline$D$ & $3.02 \times 10^{-2}$ & $\mathrm{~d}^{-1}$ & Vilas et al. 2018) & \\
\hline$P s^{*}$ & $3.16 \times 10^{6}$ & $\mathrm{CFUg}^{-1}$ & García et al. 2015) & \\
\hline$\mu_{P s}^{*}$ & $9.06 \times 10^{-4}$ & $\mathrm{~d}^{-1}{ }^{\circ} \mathrm{C}^{-2}$ & García et al. 2015) & \\
\hline$T_{P s}^{*}$ & -26 & ${ }^{\circ} \mathrm{C}$ & García et al. 2015) & \\
\hline$M I C_{P s}$ & 0.128 & $\mathrm{~kg} \mathrm{~m}^{-3}$ & Cox \& Markham & Rivero-Cruz et al., 2011) \\
\hline$S h^{*}$ & $1.82 \times 10^{6}$ & $\mathrm{CFUg}^{-1}$ & García et al. 2015 & \\
\hline$\mu_{S h}^{*}$ & $2.10 \times 10^{-3}$ & $\mathrm{~d}^{-1}{ }^{\circ} \mathrm{C}^{-2}$ & García et al. 2015) & \\
\hline$T_{S h}^{*}$ & -14 & ${ }^{\circ} \mathrm{C}$ & García et al. 2015) & \\
\hline$M I C_{S h}$ & $2.44]$ & $\mathrm{kg} \mathrm{m}^{-3}$ & Zengin \& Baysal 2015) & \\
\hline
\end{tabular}


In this section, we present the problem of optimally designing the active packaging and describe the tools required to solve such problem. The optimal design problem consists of finding the active packaging structural properties and the initial concentration of carvacrol that maximise food shelf life. Maximisation of shelf life is approached from two different points of view: use-by date maximisation (case 1) or best-before date maximisation (case 2). Structural properties that can be changed to optimally design the package are:

- Number of layers in the active packaging: 1, 2 or 3. Although packaging materials composed by more than 3 layers certainly exist, the combination of properties is generally well reproduced by considering up to 3 layers.

- Type of film for each layer: polypropylene (PP), low-density polyethylene (LDPE) or high-density polyethylene (HDPE), as the most widely used packaging materials, with different barrier properties.

- Thickness of each of the films.

The particular form of the optimisation problems will be described in the Results section.

It must be pointed out that only a limited number of configurations are allowed in the active packaging. Allowable configurations for 1,2 and 3 layers are presented in Table 4. When two or three layers are considered, the rationale for selecting the configuration is the following: a PE layer is in contact with the food product whereas a higher-barrier polymer (HDPE or PP) are placed in the outer layer (in bilayers) or in the centre of a "sandwich" configuration. Also, in multilayer configurations, the layer at the left is in contact with the environment whereas the layer at the right is in contact with the food. For instance, in the configuration PP-HDPE-LDPE, PP and LDPE are in contact with the environment and the food, respectively.

Note that the design problem is a mixed-integer programming problem since it contains discrete (number of layers and their configuration) and continuous 
Table 4: Scheme of the different configurations of the active packaging layers considered in this work. For multilayer configurations (2 or 3 layers), the layer at the left is in contact with the environment whereas the layer at the right is in contact with the food. For instance, the three layer configuration PP-HDPE-LDPE indicates that PP is in contact with the environment, LDPE is in contact with the food and HDPE is between the other two.

\begin{tabular}{ll}
\hline Number of layers & Configurations \\
\hline 1 & PP \\
& LDPE \\
& HDPE \\
& \\
& PP-LDPE \\
& HDPE-LDPE \\
& PP-HDPE \\
& \\
& PP-HDPE-LDPE \\
& LDPE-PP-LDPE \\
& LDPE-HDPE-LDPE \\
& HDPE-PP-LDPE \\
& HDPE-PP-HDPE \\
\hline
\end{tabular}

(initial carvacrol concentration in each layer and film thickness) decision variables. The presence of integer variables makes the optimisation problem much more challenging to solve. However, in this problem, the number of possible layer combinations is low enough (eleven according to Table 4) to consider all of them individually. In this way, we can remove the discrete variables from the optimisation problem. In other words, the number of layers and their configuration will not be explicitly considered in the optimisation problem as decision variables. 
Decision variables in the optimisation problem are, therefore, reduced to the thickness of the films and the initial concentration of carvacrol in each of them.

The optimisation problem is solved numerically using a hybrid (global/local)

strategy. The global optimisation approximates the neighbourhood of the global optimum whereas the local optimisation rapidly converges to the maximum of this global optimum. We have selected, for the global optimisation, the method of Differential Evolution (DE) (Storn \& Price, 1997) because of its good convergence properties. On the other hand, the Matlab algorithm fmincon, in particular, the interior point method (Byrd et al. 2000), has been chosen for the local search. Regarding time integration, we have used the Matlab function ode15s, with the default numerical differentiation formulas, because of its capacity to solve stiff systems.

\section{Results}

325 The objective is to design the package system to maximise use-by date (Case 1); best-before date (Case 2); and to assess the changes in food shelf life due to variations on the transport/storage temperature profile and on the time span between package manufacturing and packaging contact with the food (Case 3). Estimations of use-by date rely solely on safety criteria whereas best-before date labelling is a more restrictive date relying on both safety and quality standards. As mentioned above, Listeria monocytogenes concentration and $K_{I}$-value are selected as safety and quality indicators, respectively. The Matlab ${ }^{\mathrm{TM}}$ codes used in the different case studies are available at https://doi.org/10.5281/ zenodo.3244153.

3.1. Case 1: Active packaging design to extend use-by date

The objective is to select the active packaging film materials, their thicknesses ( $L_{i}$ with $\left.i=1,2,3\right)$ as well as the initial concentration of carvacrol in each of them $\left(C_{i, 0}\right)$ to maximise the use-by date $\left(t_{f}\right)$. Mathematically this 
expressed as:

$$
\begin{array}{cl}
\underset{t_{f}, L_{i}, C_{i, 0}}{\operatorname{maximise}} & \text { Use-by date }\left(t_{f}\right) \\
\text { subject to } & \text { Safety constraints, } \\
& \text { Design constraints. }
\end{array}
$$

We consider, in this case study, ideal transport and storage conditions with constant room temperature $T(t)=3{ }^{\circ} \mathrm{C}$. However, the methodology allows considering other cases such as time-varying profiles (see section 3.3).

The use-by date is based on safety requirements. For fresh fish products safety is defined as the amount of time required to reach $100 \mathrm{CFU} / \mathrm{g}$ of Listeria monocytogenes. This constraint is based on EFSA recommendations Commission of the European Communities, 2005). On the other hand, carvacrol has an effect on the organoleptic properties of food and, at large concentrations, it causes safety problems. As a result, there is a limit on carvacrol concentration allowed in the food matrix. Based on maximum concentrations reported in food and beverages (Burdock, 2010), we fix a limit of $0.03 \mathrm{~kg} / \mathrm{m}^{3}=30 \mathrm{ppm}$. This limiting carvacrol concentration avoids excessive oregano-like flavour and it is significantly lower than the reported toxicity levels of carvacrol in the literature (Suntres et al. 2015). Therefore, the optimisation is subject to the following constraints:

- Listeria concentration at final time-Equation 12 -: $\operatorname{Lm}\left(t_{f}\right) \leq 100 \mathrm{CFU} / \mathrm{g}$.

- Concentration of carvacrol in the food at all times -Equation (5)-: $C_{f}(t) \leq$ $0.03 \mathrm{~kg} / \mathrm{m}^{3}$.

In practice, taking into account reasonable costs for food packages, bounds must be considered for film thickness. After stretching, the minimum layer thickness lies around 10-12 $\mu \mathrm{m}$ considering that PE and PP can be processed without tie layers given their compatibility (Butler \& Morris, 2010). Additionally, fish primary packaging has a gauge between 40-90 $\mu \mathrm{m}$ with a growing tendency to thinner packaging. Although up to seven or even nine layers are possible in multilayers, two or three layers are still the most commonly used. 
Finally, maximum carvacrol initial concentration in each layer must be taken into account. Hence, we consider the following bounds on the decision variables:

- Thickness of each individual layer: $12 \times 10^{-6} \mu \mathrm{m} \leq L_{i} \leq 70 \times 10^{-6} \mu \mathrm{m}$.

- Total thickness of the active packaging: $35 \times 10^{-6} \mu \mathrm{m} \leq L \leq 70 \times 10^{-6} \mu \mathrm{m}$.

365

- Initial concentration of carvacrol in each layer (Cerisuelo et al. 2013): $C_{i, 0} \leq 80 \mathrm{~kg} / \mathrm{m}^{3}$.

Optimisation results are summarised in Table 5 . Each row corresponds to one of the considered designs, being the first row the case without carvacrol (no active packaging).

We observe that the use-by date is either (1) similar to the case without carvacrol, i.e. $t_{f}$ close to $13.5 \mathrm{~d}$, or (2) extended to values close to $15.8 \mathrm{~d}$. The reported value for HDPE carvacrol diffusivity is very low, so its release into the food compartment is much slower than in the other two cases (PP, LDPE). As a consequence, when HDPE is the layer in contact with the food, release of carvacrol is considerably slow. Therefore L. monocytogenes concentration reaches the safety constraint before any inhibitory effect can be appreciated.

The best designs use LDPE for the layer in contact with the food. LDPE has the largest carvacrol diffusivity which is equivalent to quickly transferring the carvacrol to the food product and inhibiting the growth of pathogens. Such strategy is limited by the maximum amount of carvacrol allowable in the food product $\left(0.03 \mathrm{~kg} \mathrm{~m}^{-3}\right)$. A slight improvement can be achieved by using bior trilayers where LDPE is in contact with the food product. Again, LDPE inhibits the growth of pathogens right after the contact and the other layers act as reservoir steadily releasing carvacrol. Note also that the length of LDPE in contact with the food corresponds with the minimum allowed (35 $\mu \mathrm{m}$ for monolayer and $12 \mu \mathrm{m}$ for multilayer).

Figure 2 shows the evolution of Listeria monocytogenes and carvacrol concentration in the food. Blue lines correspond to the best configuration of the active packaging (LDPE-PP-LDPE). Black lines represent the simulation results 
Table 5: Optimal designs of active packaging to extend the use-by date $\left(t_{f}\right)$ First row corresponds with the control case (without carvacrol). $C_{i, 0}$ represents initial concentration of carvacrol in layer $i . L_{i}$ corresponds with the size of layer $i$. Units are: $[\mathrm{d}]$ for time, $\left[\mathrm{kg} / \mathrm{m}^{3}\right]$ for concentration, and $[\mu \mathrm{m}]$ for layer sizes.

\begin{tabular}{llllllll}
\hline Layer & \multirow{2}{*}{ Use-by date } & \multicolumn{2}{c}{$\mathbf{1}^{\text {st }}$ layer } & \multicolumn{2}{c}{$\mathbf{2}^{\text {nd }}$ layer } & \multicolumn{2}{c}{$\mathbf{3}^{\text {rd }}$ layer } \\
configuration & $t_{f}$ & $C_{1,0}$ & $L_{1}$ & $C_{2,0}$ & $L_{2}$ & $C_{3,0}$ & $L_{3}$ \\
\hline- & 13.43 & - & - & - & - & - & - \\
& & & & & & & \\
PP & 14.94 & 49.2 & 70.0 & - & - & - & - \\
LDPE & 15.69 & 18.2 & 35.0 & - & - & - & - \\
HDPE & 13.51 & 80.0 & 70.0 & - & - & - & - \\
& & & & & & & \\
PP-LDPE & 15.78 & 3.4 & 39.1 & 47.7 & 12.0 & - & - \\
PP-HDPE & 13.51 & 66.9 & 56.7 & 80.0 & 13.3 & - & - \\
HDPE-LDPE & 15.78 & 3.6 & 39.1 & 47.2 & 12.0 & - & - \\
& & & & & & & \\
PP-HDPE-LDPE & 15.78 & 57.0 & 13.3 & 3.6 & 42.2 & 48.7 & 12.0 \\
LDPE-PP-LDPE & 15.78 & 3.9 & 29.8 & 3.0 & 16.0 & 48.8 & 12.0 \\
LDPE-HDPE-LDPE & 15.78 & 57.0 & 13.3 & 3.6 & 42.2 & 48.7 & 12.0 \\
HDPE-PP-LDPE & 15.78 & 15.6 & 20.6 & 2.5 & 13.7 & 48.5 & 12.1 \\
HDPE-PP-HDPE & 13.51 & 78.9 & 33.0 & 17.0 & 23.8 & 80.0 & 13.3 \\
\hline
\end{tabular}
lines indicate admissible limits for the variable.

The best design extends the use-by date by $18 \%$ when compared with the control case. The improvement relates to the rapid release of carvacrol without exceeding the limit of $0.03 \mathrm{~kg} / \mathrm{m}^{3}$. 

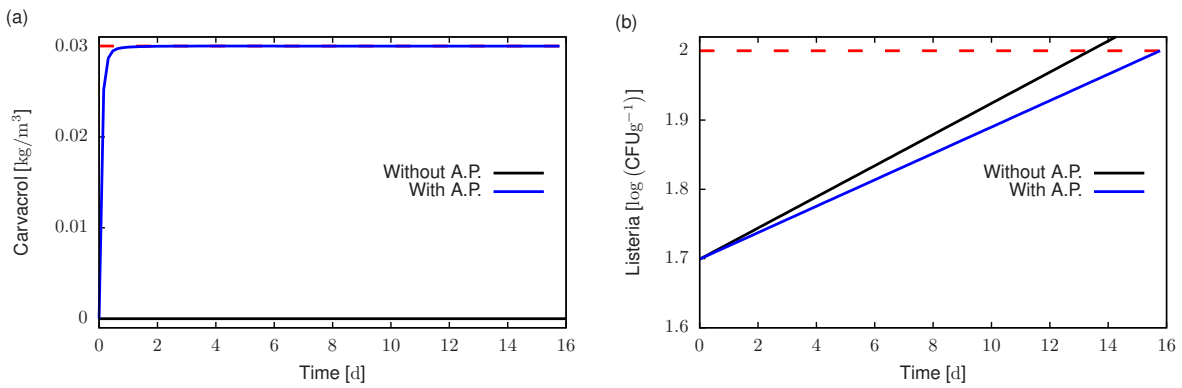

Figure 2: Time evolution of (a) carvacrol concentration in food; (b) Listeria monocytogenes. The figure corresponds with the LDPE-PP-LDPE configuration and room temperature is kept constant at $3{ }^{\circ} \mathrm{C}$. Black line corresponds with the case where no active packaging is used. Dashed lines indicate bounds on the variables.

The objective is similar to the previous case but maximising best-before date instead of use-by date, and therefore, requiring standards for both food safety and quality. Mathematically, the problem is stated as:

$$
\begin{array}{cl}
\underset{t_{f}, L_{i}, C_{i, 0}}{\operatorname{maximise}} & \text { Best-before date }\left(t_{f}\right) \\
\text { subject to } & \text { Quality constraints, } \\
& \text { Safety constraints, } \\
& \text { Design constraints. }
\end{array}
$$

As in the previous case, constant profile in room temperature is assumed $T(t)=$ $3{ }^{\circ} \mathrm{C}$.

Safety and design constraints correspond with the ones selected in case 1 (Section 3.1), but the optimisation is now also subject to quality constraints. In this regard, and for fish products, $K_{I}$ values below $50 \%$ are considered modprately fresh whereas values above $70 \%$ indicate that fish is not fresh Saito et al. 1959: Ocaño-Higuera et al. 2011). Therefore, the following constraints are considered for the solution of the optimisation problem:

- Listeria concentration at final time-Equation 12 -: $\operatorname{Lm}\left(t_{f}\right) \leq 100 \mathrm{CFU} / \mathrm{g}$. 
- Concentration of carvacrol in the food at all times -Equation (5)-: $C_{f}(t) \leq$ $0.03 \mathrm{~kg} / \mathrm{m}^{3}$.

- $K_{I}$-value at final time: $K_{I}\left(t_{f}\right) \leq 50 \%$.

Table 6 summarises the results of the optimisations for different designs. First row corresponds to the case without active packaging (control case). Best-

Table 6: Optimal designs of active packaging to extend best-before date $\left(t_{f}\right)$ while guaranteeing food safety and quality. First row corresponds with the control case (without carvacrol). $C_{x, 0}$ represents initial concentration of carvacrol in layer $x . L_{x}$ corresponds with the size of layer $x$. Units are: $[\mathrm{d}]$ for time, $\left[\mathrm{kg} / \mathrm{m}^{3}\right]$ for concentration, and $[\mu \mathrm{m}]$ for layer sizes.

\begin{tabular}{lccccccc}
\hline \multirow{2}{*}{$\begin{array}{l}\text { Layer } \\
\text { configuration }\end{array}$} & Best-before date & \multicolumn{2}{c}{$\mathbf{1}^{\text {st }}$ layer } & \multicolumn{2}{c}{$\mathbf{2}^{\text {nd }}$ layer } & \multicolumn{2}{c}{$\mathbf{3}^{\text {rd }}$ layer } \\
\hline & $t_{f}$ & $C_{1,0}$ & $L_{1}$ & $C_{2,0}$ & $L_{2}$ & $C_{3,0}$ & $L_{3}$ \\
\hline & 7.40 & - & - & - & - & - & - \\
PP & & & & & & & \\
LDPE & 8.58 & 63.9 & 70.0 & - & - & - & - \\
HDPE & 9.11 & 18.2 & 35.0 & - & - & - & - \\
& 7.44 & 80.0 & 70.0 & - & - & - & - \\
PP-LDPE & & & & & & & \\
PP-HDPE & 9.20 & 3.0 & 56.6 & 48.6 & 12.0 & - & - \\
HDPE-LDPE & 7.44 & 67.0 & 19.8 & 80.0 & 50.2 & - & - \\
& 9.20 & 3.6 & 37.0 & 47.2 & 12.0 & - & - \\
PP-HDPE-LDPE & & & & & & & \\
LDPE-PP-LDPE & 9.20 & 0.0 & 31.5 & 3.6 & 16.5 & 48.8 & 12.0 \\
LDPE-HDPE-LDPE & 9.20 & 11.7 & 23.8 & 2.9 & 24.4 & 49.4 & 12.0 \\
HDPE-PP-LDPE & 9.20 & 69.3 & 15.9 & 3.6 & 32.1 & 48.7 & 12.0 \\
HDPE-PP-HDPE & 9.20 & 28.5 & 30.4 & 2.5 & 17.7 & 49.5 & 12.0 \\
\hline & 7.44 & 77.7 & 14.4 & 79.9 & 42.3 & 80.0 & 13.3 \\
\hline
\end{tabular}



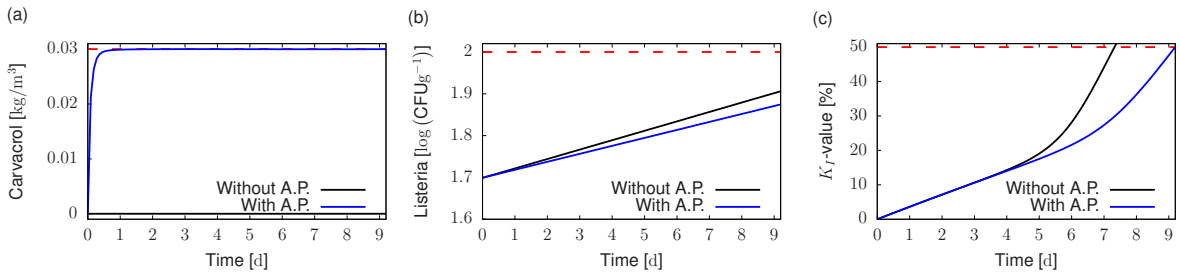

Figure 3: Time evolution of (a) carvacrol concentration in food; (b) Listeria monocytogenes; and (c) $K_{I}$-value for the second case study. The figure corresponds with the LDPE-PP-LDPE configuration and room temperature is kept constant at $3{ }^{\circ} \mathrm{C}$. Black line corresponds with the case where no active packaging is used. Dashed lines indicate bounds on the variables.

are obtained with the configurations where carvacrol diffuses rapidly to reach the selected constraint of $C_{f}(t)=0.03 \mathrm{~kg} / \mathrm{m}^{3}$.

\subsection{Case 3: Effect on shelf life of transport/storage temperature profiles and} packaging storage after manufacturing

As discussed in Jedermann et al. (2014), shelf life is a dynamic value related to the actual quality and environmental conditions history that goes beyond any static use-by and best-before date. In this section, we will study the effect, on the $K_{I}$-value, of changes in (i) the transport/storage temperature; and (ii) the 

with the food matrix.

For the first case, we implement different time-temperature profiles simulating different abusive temperatures during transport/storage (see Figure 4(a)). We have chosen 50 randomly generated profiles in order to cover a wide range of possibilities. Transport and storage temperature is assumed to be $3{ }^{\circ} \mathrm{C}$. However, at a given time a perturbation is introduced in the storage temperature to simulate the effect of a malfunction on the temperature control devices. Perturbations have a maximum value of $30^{\circ} \mathrm{C}$, and their duration vary between 1 and 8 h. The specific value of the perturbation, the moment at which the perturbation occurs and its duration are randomly chosen as shown in Figure 4(a). Figures
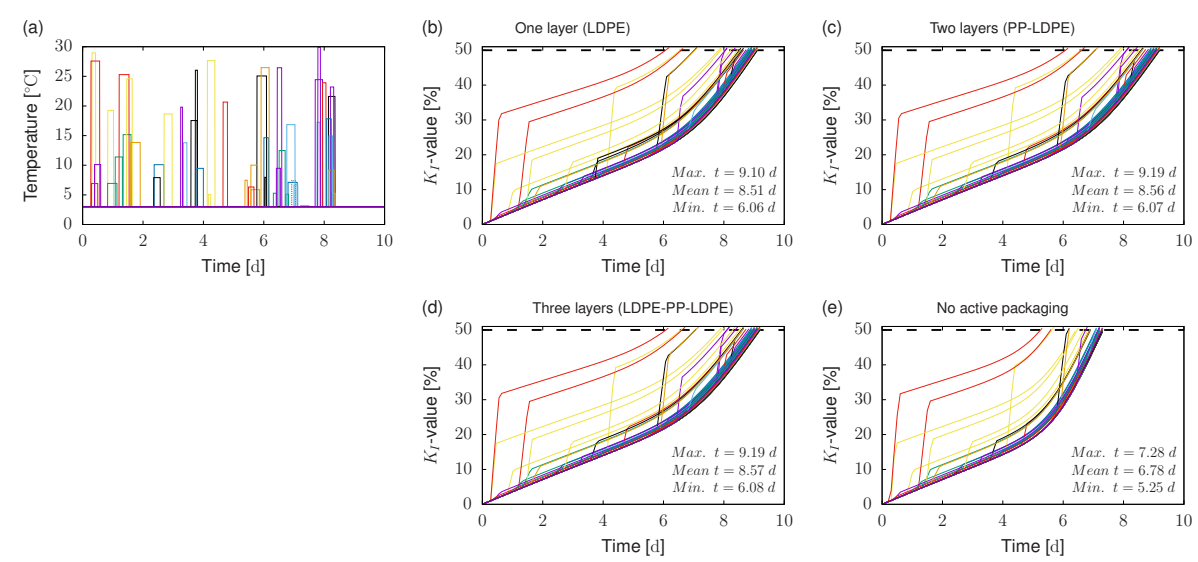

Figure 4: (a) Time-temperature storage profiles used in case study 3. (b)-(e) Evolution of the $K_{I}$-value in the food using the time-temperature storage profiles of Figure 4 (a). Figures (b)-(d) correspond, respectively, to one layer, two layers and three layers cases. Figure (e) presents the results obtained when no active packaging is considered. Colours used in $K_{I}$ evolution figures correspond to the colours used in the time-temperature profiles. Horizontal dashed line indicate bound on the variable. Maximum, mean and minimum values of the best-before date for each of the cases are also indicated.

440

4(b)-(d) show the effect of these time-temperature profiles on the $K_{I}$-value for the best monolayer, bilayer and trilayer configurations, respectively. The three configurations resulted in almost equivalent $K_{I}$-values, as expected from the results obtained in the previous section. Shelf life (time for the $K_{i}$-value to reach 
$50 \%$ ) vary between $6.2 \mathrm{~d}$ and $9.2 \mathrm{~d}$. Finally, Figure $4(\mathrm{e})$ corresponds to the case without active packaging. Considering active packaging increases shelf life, in mean value, around $20 \%$.

Temperature profiles of Figure 4(a) have also an impact on the maximum carvacrol concentration on the fish fillet surface. In most of the cases, such concentration remains below the maximum allowed $\left(0.03 \mathrm{~kg} \mathrm{~m}^{-3}\right)$. However, when considering three layers, some of those profiles result in maximum carvacrol concentrations of around $0.031 \mathrm{~kg} \mathrm{~m}^{-3}$, i.e. above the constraint. The smart active packaging approach allows evaluating safety and quality criteria under unexpected storage perturbations.

In multilayer configurations, carvacrol concentration varies within the different layers even if the packaging is not in contact with the food. In other words, after packaging manufacturing and before packaging use, carvacrol concentration will change within the layers. The procedure proposed in this work allows us to take these changes into account. The aim of the second test is to evaluate the effect, on the $K_{I}$ value, of the time span between packaging manufacturing and packaging use. To that purpose we perform two simulations. The first simulation is carried out to obtain the carvacrol distribution in the layers just before the package is used to wrap the food. In the second simulation, we use such distribution as initial conditions for the package/food model.

Before the package is used, the model describing the evolution of carvacrol within the layers is formed by equations $(1)-(3)$ and

$$
\left.\frac{\partial C_{n}}{\partial x}\right|_{x=H}=0,
$$

indicating that no flux of carvacrol is considered between the right boundary and the outer environment. Using this model we obtain the concentration of carvacrol in the package at different times $(t=0,3,6,12,18,24,30)$, see Figures 5(a) and 5(c) for two layer (PP-PDE) and three layer (LDPE-PP-LDPE) configurations, respectively.

As mentioned above, the results of such simulations are used as initial conditions for the model that considers both package and food, i.e. Eqs. (1) - 19), 
to evaluate the effect of packaging storage time on the $K_{I}$-value. Such effect is represented in Figures 5(b) and 5(d). As shown in the figures, variations in
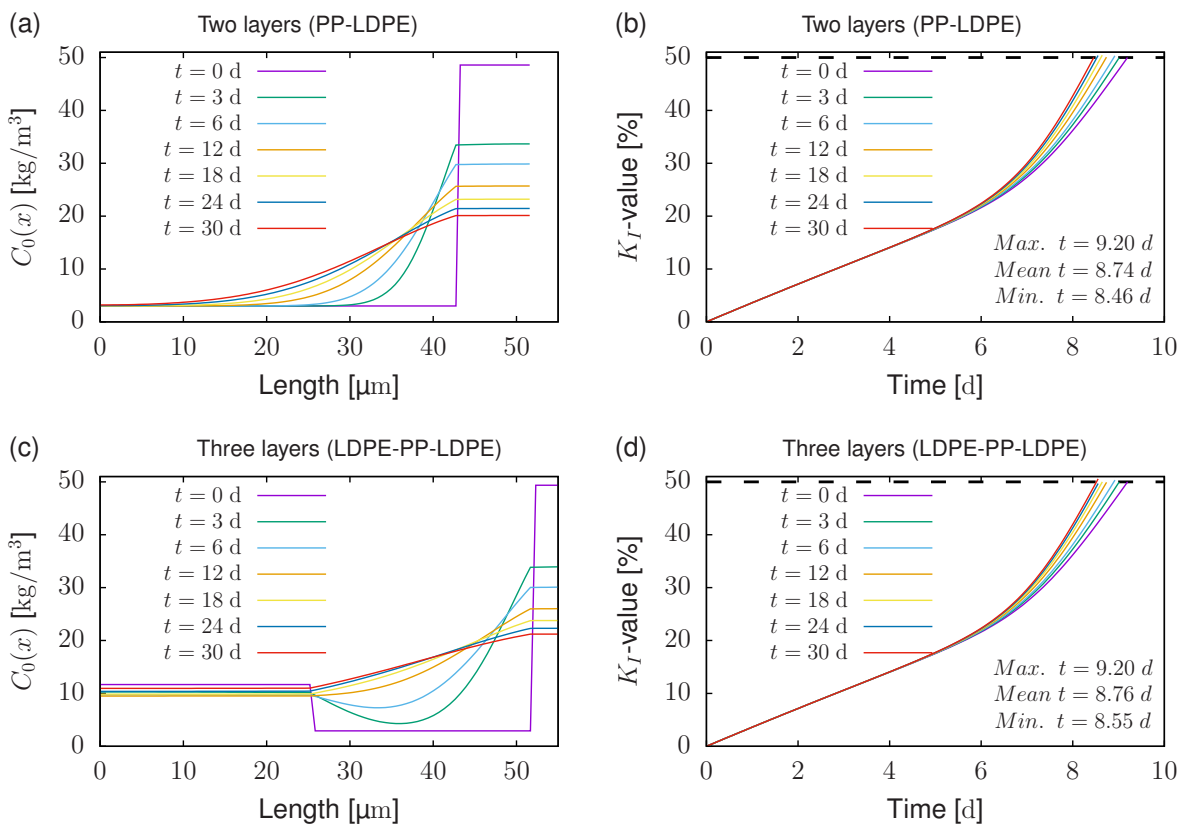

Figure 5: (a) Carvacrol distribution in a two layer package during storage and before it is used to wrap the food. (b) Evolution of the $K_{I}$ value in the food using the concentrations in Figure 5.a) as initial conditions. (c) Carvacrol distribution in a three layer package during storage and before it is used to wrap the food. (d) Evolution of the $K_{I}$ value in the food using the concentrations in Figure 5(c) as initial conditions.

475

shelf life of around half a day are produced depending on the time at which the food product is wrapped after package manufacturing. For the one-layer case, carvacrol remains constant during storage because no gradient is considered in the initial conditions. This implies that, depending on the storage time of the package without food, one layer configurations may result more advantageous than two or three layers. In this case study, maximum carvacrol constraint is fulfilled independently of the package storage time. 


\section{Discussion and Conclusions}

In this work, we have developed a methodology to optimally design smart

485 methodology consists of a system of methods, for modelling and optimization, with different mathematical models to estimate shelf life under changing storage and transport conditions. We envision that this methodology will reduce the experimental work by previously detecting those configurations that could be 
concentration allowed in the food matrix. This issue can be handled by introducing the initial carvacrol concentration in the different layers as a decision variable in the optimisation problem.

From the three considered film materials, LDPE has the largest carvacrol diffusivity. Therefore, the best results select this material to be in contact with the food. Optimal initial carvacrol concentration in this layer is around half of the maximum allowed. Therefore, the seemingly optimal strategy is to release carvacrol quickly to avoid the growth of microorganisms as soon as possible. It should be noted that multilayers can release the active agent gradually along storage time, which is also advantageous. If the product is consumed soon after packing, a multilayer configuration has less impact on the product organoleptic properties since only a low amount of active agent has been transferred. However, as storage time increases, a higher amount of active agent can pre${ }_{525}$ vent its early spoilage. It can be concluded that mono- or multilayered can serve for different purposes and types of products. The methodology proposed here can help decide which one is the most suitable choice for each specific case. In our case study, results show that, from the point of view of shelf life extension, two-layer configurations are equivalent to three-layer configurations whereas one-layer configurations perform slightly worse if the package is used immediately after manufacturing. However, if the package is stored before its use, then monolayers configurations might be preferred depending on the storage time.

Results also show that constraints in best-before date are more restrictive than use-by date constraints. Therefore, when both are considered, the $K_{I}$-value determines the design and shelf life of the smart active packaging system. We should also note that the $K_{I}$-value continues increasing even if the antimicrobial completely inhibits the growth of spoilage bacteria. Therefore, active packaging can reduce food spoilage rate but it cannot stop it.

${ }_{540}$ Several issues should be considered when extrapolating the results to other systems: (i) parameters were obtained from the literature for the case of retail fresh hake (for other food products such parameters should be re-estimated); 
(ii) biochemical routes for quality degradation will change for other food products such as meat; (iii) bacterial growth models used in this work assumed that microorganisms are fully adapted and, as a consequence, no lag phase is considered. Regarding the last consideration, we should note that lag phase models are highly uncertain as they depend on numerous factors related to the food matrix. Considering no lag phase represents the worst-case scenario, and the safest one, and allows the use of a deterministic modelling approach, even when population numbers are low (García et al. 2018). This is a well-established assumption, used for example by EFSA when assessing the influence of temperature on different fish hazards EFSA (European Food Safety Authority) (2015).

The virtual system developed in this work can be easily adapted to other food matrices and antimicrobials using predictive models described in the literature or in specific databases. Many scientific publications incorporate nowadays software code that facilitates this task. Besides, there are several databases for predictive modelling, which consider different food matrices, that can be used -see, for instance, ComBase (http://www.combase.cc) or the Food Spoilage and Safety Predictor (FSSP) (http://fssp.food.dtu.dk/)-. These models are commonly used to assess different food quality and safety aspects EFSA (European Food Safety Authority) (2015).

Finally, the virtual system described in this work is sufficiently generic to incorporate online information from hardware sensors that would improve shelf life estimations. The most common example is the use of sensors such as thermocouples or PT-100 to obtain online storage temperature measurements. Such data can be introduced in the models to update shelf life estimations. However, we envision its potential to incorporate measurements, related to food quality and safety indicators, from new hardware sensors that are being currently under development. For example, nowadays there exist non-invasive devices to detect and measure bacterial pathogens or spoilers, such as Listeria monocytogenes, Escherichia coli or Pseudomonas, in food products (Aït-Kaddour et al. 2011 Abdelhaseib et al. 2019). On the other hand, (ElMasry et al., 2016) presented a non-invasive sensing method, based on fluorescence spectroscopy, to measure 


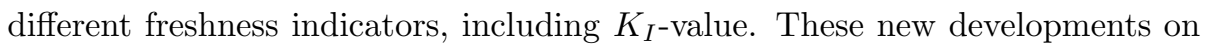
the smart part of the package can be used, in combination with our virtual smart packaging system, to provide more reliable predictions of the evolution of shelf life under changing conditions in the food chain.

\section{Acknowledgements}

C.V. acknowledges funding received from the European Union's Horizon 2020 research and innovation programme under grant agreement No 723575 (CoPro project). M.M.I belongs to the Galician Competitive Research Group (ED431C 2017/029) and the CRETUS strategic partnership (AGRUP2017/01), co-funded by FEDER (EU). M.R.G acknowledges financial support through the projects IMMICRO (201870E134) and ControlAR (RTI2018-093560-J-I00, MCIU/AEI/FEDER, UE)

\section{References}

Abdelhaseib, M. U., Singh, A. K., \& Bhunia, A. K. (2019). Simultaneous detection of Salmonella enterica, Escherichia coli and Listeria monocytogenes in food using a light scattering sensor. Journal of Applied Microbiology, 126, 1496-1507.

Aït-Kaddour, A., Boubellouta, T., \& Chevallier, I. (2011). Development of a portable spectrofluorimeter for measuring the microbial spoilage of minced beef. Meat Science, 88, 675-681.

Antunes-Rohling, A., Artaiz, Á., Calero, S., Halaihel, N., Guillén, S., Raso, J., ${ }_{595}$ Álvarez, I., \& Cebrián, G. (2019). Modelling microbial growth in modifiedatmosphere-packed hake (Merluccius merluccius) fillets stored at different temperatures. Food Research International, 122, 506-516.

Augustin, J. C., \& Carlier, V. (2000a). Mathematical modelling of the growth rate and lag time for Listeria monocytogenes. International Journal of Food Microbiology, 56, 29-51. 
Augustin, J.-C., \& Carlier, V. (2000b). Modelling the growth rate of Listeria monocytogenes with a multiplicative type model including interactions between environmental factors. International Journal of Food Microbiology, 56, $53-70$.

Bajard, S., Rosso, L., Fardel, G., \& Flandrois, J. P. (1996). The particular behaviour of Listeria monocytogenes under sub-optimal conditions. International Journal of Food Microbiology, 29, 201-211.

Baranyi, J., \& Roberts, T. A. (1994). A dynamic approach to predicting bacterial growth in food. International Journal of Food Microbiology, 23, 277-294.

Ben Arfa, A., Combes, S., Preziosi-Belloy, L., Gontard, N., \& Chalier, P. (2006). Antimicrobial activity of carvacrol related to its chemical structure. Letters in Applied Microbiology, 43, 149-154.

Benabbou, R., Subirade, M., Desbiens, M., \& Fliss, I. (2018). The Impact of Chitosan-Divergicin Film on Growth of Listeria monocytogenes in ColdSmoked Salmon. Frontiers in Microbiology, 9, 1-10.

Burdock, G. A. (2010). Fenaroli's handbook of flavor ingredients. CRC press. doi:10.1016/S0015-6264(76)80260-X.

Butler, T. I., \& Morris, B. A. (2010). Chapter 15 - PE based multilayer film structures. In J. R. Wagner (Ed.), Multilayer Flexible Packaging. Plastics 620 Design Library (pp. 205 - 230). Elsevier, Boston, USA. doi:https://doi. org/10.1016/B978-0-8155-2021-4.10015-2.

Byrd, R. H., Gilbert, J. C., \& Nocedal, J. (2000). A trust region method based on interior point techniques for nonlinear programming. Mathematical Programming, 89, 149-185.

${ }_{625}$ Cerisuelo, J. P., Bermúdez, J. M., Aucejo, S., Catalá, R., Gavara, R., \& Hernández-muñoz, P. (2013). Describing and modeling the release of an antimicrobial agent from an active $\mathrm{PP} / \mathrm{EVOH} / \mathrm{PP}$ package for salmon. Journal of Food Engineering, 116, 352-361. 
Cerisuelo, J. P., Muriel-galet, V., Bermúdez, J. M., Aucejo, S., Catalá, R.,

Gavara, R., \& Hernández-Muñoz, P. (2012). Mathematical model to describe the release of an antimicrobial agent from an active package constituted by carvacrol in a hydrophilic EVOH coating on a PP film. Journal of Food Engineering, 110, 26-37.

Chaix, E., Couvert, O., Guillaume, C., Gontard, N., \& Guillard, V. ${ }_{635}$ (2015). Predictive Microbiology Coupled with Gas (O2/CO2) Transfer in Food/Packaging Systems: How to Develop an Efficient Decision Support Tool for Food Packaging Dimensioning. Comprehensive Reviews in Food Science and Food Safety, 14, 1-21.

Commission of the European Communities (2005). Commission Regulation (EC) No 2073/2005 on microbiological criteria for foodstuffs. Official Journal n of the European Union, (pp. L338, 1-26). URL: https://eur-lex.europa. eu/legal-content/EN/TXT/HTML/?uri=CELEX : 32005R2073\{\&\}from=EN

Cox, S. D., \& Markham, J. L. (2007). Susceptibility and intrinsic tolerance of Pseudomonas aeruginosa to selected plant volatile compounds. Journal of 645 Applied Microbiology, 103, 930-936.

Dalgaard, P. (1995). Modelling of microbial activity and prediction of shelf life for packed fresh fish. International Journal of Food Microbiology, 26, 305-317.

Dillon, R. M., \& Patel, T. R. (1992). Listeria in Seafoods: A Review. Journal of Food Protection, 55, 1009-1015.

EFSA (European Food Safety Authority) (2015). Scientific and technical assistance on the evaluation of the temperature to be applied to pre-packed fishery

口 products at retail level. EFSA Journal, 13, 4162. doi:10.2903/j.efsa. 2015. 4162 .

655 ElMasry, G., Nakazawa, N., Okazaki, E., \& Nakauchi, S. (2016). Non- 
invasive sensing of freshness indices of frozen fish and fillets using pretreated excitation-emission matrices. Sensors and Actuators B, 228, 237-250.

EU Commission (2004). Regulation (EC) No 852/2004. Technical Report

п May 2002. URL: http://eur-lex.europa.eu/LexUriServ/LexUriServ. do?uri=0J:L:2004:139:0001:0054:en:PDF

EUMOFA (European Market Observatory for Fisheries and Aquaculture Products) (2017). The EU Fish Market 2017 Edition. Technical Re-

a port. URL: http://wWw.eumofa.eu/documents/20178/108446/The+EU+ fish+market+2017.pdf.

${ }_{665}$ García, M. R., \& Cabo, M. L. (2018). Optimization of E. coli Inactivation by Benzalkonium Chloride Reveals the Importance of Quantifying the Inoculum Effect on Chemical Disinfection. Frontiers in Microbiology, 9, 1-14.

García, M. R., Cabo, M. L., Herrera, J. R., Ramilo-Fernández, G., Alonso, A. A., \& Balsa-Canto, E. (2017). Smart sensor to predict retail fresh fish quality under ice storage. Journal of Food Engineering, 197, 87-97.

García, M. R., Vázquez, J. A., Teixeira, I. G., \& Alonso, A. A. (2018). Stochastic individual-based modeling of bacterial growth and division using flow cytometry. Frontiers in Microbiology, 8, 1-12.

García, M. R., Vilas, C., Herrera, J. R., Bernárdez, M., Balsa-Canto, E., \& Alonso, A. A. (2015). Quality and shelf-life prediction for retail fresh hake (Merluccius merluccius). International journal of food microbiology, 208, 6574 .

Giannoglou, M., Touli, A., Platakou, E., Tsironi, T., \& Taoukis, P. S. (2014). Predictive modeling and selection of TTI smart labels for monitoring the quality and shelf-life of frozen seafood. Innovative Food Science 83 Emerging Technologies, 26, 294-301.

Gram, L., \& Dalgaard, P. (2002). Fish spoilage bacteria - problems and solutions. Current Opinion in Biotechnology, 13, 262-266. 
Guillard, V., Gaucel, S., Fornaciari, C., Angellier-Coussy, H., Buche, P., \&

Gontard, N. (2018). The Next Generation of Sustainable Food Packaging to Preserve Our Environment in a Circular Economy Context. Frontiers in Nutrition, 5, 121.

Hong, H., Regenstein, J. M., \& Luo, Y. (2017). The importance of ATP-related compounds for the freshness and flavor of post-mortem fish and shellfish muscle: A review. Critical Reviews in Food Science and Nutrition, 57, 1787-1798.

Jedermann, R., Nicometo, M., Uysal, I., \& Lang, W. (2014). Reducing food losses by intelligent food logistics. Philosophical Transactions of the Royal Society A: Mathematical, Physical and Engineering Sciences, 372, 1-20.

Karube, I., Matsuoka, H., Suzuki, S., Watanabe, E., \& Toyama, K. (1984). Determination of fish freshness with an enzyme sensor system. Journal of Agricultural and Food Chemistry, 32, 314-319.

Krepker, M., Prinz-Setter, O., Shemesh, R., Vaxman, A., Alperstein, D., \& Segal, E. (2018). Antimicrobial Carvacrol-Containing Polypropylene Films: Composition, Structure and Function. Polymers, 10, 79.

Li, D., Qin, N., Zhang, L., Li, Q., Prinyawiwatkul, W., \& Luo, Y. (2019). Degradation of adenosine triphosphate, water loss and textural changes in frozen common carp (Cyprinus carpio) fillets during storage at different temperatures. International Journal of Refrigeration, 98, 294-301.

Martinez-Lopez, B., Peyron, S., Gontard, N., \& Mauricio-Iglesias, M. (2015). Practical Identifiability Analysis for the Characterization of Mass Transport Properties in Migration Tests. Industrial 85 Engineering Chemistry Research, $54,4725-4736$.

Mauricio-Iglesias, M., Guillard, V., Gontard, N., \& Peyron, S. (2009). Application of FTIR and Raman microspectroscopy to the study of food/packaging interactions. Food Additives and Contaminants - Part A Chemistry, Analysis, Control, Exposure $\&$ Risk Assessment, 26, 1515-1523. 
Ocaño-Higuera, V., Maeda-Martínez, A., Marquez-Ríos, E., CanizalesRodríguez, D., Castillo-Yáñez, F., Ruíz-Bustos, E., Graciano-Verdugo, A., \& Plascencia-Jatomea, M. (2011). Freshness assessment of ray fish stored in ice by biochemical, chemical and physical methods. Food Chemistry, 125, $49-54$.

Otero-Tuárez, V., Carrión-Granda, X., Fernández-Pan, I., Fernández, T., \& Maté, J. I. (2019). Combined effect of antimicrobial edible coatings with reduction of initial microbial load on the shelf-life of fresh hake (Merluccius merluccius) medallions. International Journal of Food Science 8 Technology, $54,835-843$.

Pacquit, A., Frisby, J., Diamond, D., Lau, K. T., Farrell, A., Quilty, B., \& Diamond, D. (2007). Development of a smart packaging for the monitoring of fish spoilage. Food Chemistry, 102, 466-470.

725 Peltzer, M., Magner, J., Jiménez, A., Additives, F., Peltzer, M., Magner, J., \& Jiménez, A. (2009). Migration study of carvacrol as a natural antioxidant in high-density polyethylene for active packaging. Food Additives and Contaminants, 26, 938-946.

Pol, I. E., \& Smid, E. J. (1999). Combined action of nisin and carvacrol on Bacillus cereus and Listeria monocytogenes. Letters in Applied Microbiology, 29, 166-170.

Proctor, B. E., \& Nickerson, J. T. R. (1935). An investigation of the sterility of fish tissues. Journal of Bacteriology, 4, 377-382.

Rivero-Cruz, I., Duarte, G., Navarrete, A., Bye, R., Linares, E., \& Mata, R. (2011). Chemical Composition and Antimicrobial and Spasmolytic Properties of Poliomintha longiflora and Lippia graveolens Essential Oils. Journal of Food Science, 76, 309-317.

Roca, E., Broyart, B., Guillard, V., Guilbert, S., \& Gontard, N. (2008). Pre- 
dicting moisture transfer and shelf-life of multidomain food products. Journal

Rosso, L., Lobry, J. R., Bajard, S., \& Flandrois, J. P. (1995). Convenient model to describe the combined effects of temperature and $\mathrm{pH}$ on microbial growth. Applied and Environmental Microbiology, 61, 610-616.

Rupika, L. A. S. (2010). Development and Evaluation of Antimicrobial Food

Saito, T., Arai, K.-i., \& Matsuyoshi, M. (1959). A New Method for Estimating the Freshness of Fish. Bulletin of the Japanese Society of Scientific Fisheries, 24, 749-750.

Storn, R., \& Price, K. (1997). Differential Evolution - A Simple and Efficient Heuristic for global Optimization over Continuous Spaces. Journal of Global Optimization, 11, 341-359.

Suntres, Z. E., Coccimiglio, J., \& Alipour, M. (2015). The Bioactivity and Toxicological Actions of Carvacrol. Critical Reviews in Food Science and Nutrition, 55, 304-318.

Vilas, C., Alonso, A. A., Herrera, J. R., Bernárdez, M., \& García, M. R. (2018). A mathematical model to predict early quality attributes in hake during storage at low temperature. Journal of Food Engineering, 222, 11-19.

Vilas, C., Alonso, A. A., Herrera, J. R., García-Blanco, A., \& García, M. R. (2017). A model for the biochemical degradation of inosine monophosphate in hake (Merluccius merluccius). Journal of Food Engineering, 200, 95-101.

Wyrwa, J., \& Barska, A. (2017). Innovations in the food packaging market: active packaging. European Food Research and Technology, 243, 1681-1692.

Yam, K. L., Takhistov, P. T., \& Miltz, J. (2005). Intelligent Packaging: Concepts and Applications. Journal of Food Science, 70, R1-R10. 
Zengin, H., \& Baysal, A. H. (2015). Antioxidant and Antimicrobial Activities of Thyme and Clove Essential Oils and Application in Minced Beef. Journal of Food Processing and Preservation, 39, 1261-1271.

Zhang, H., Hortal, M., Dobon, A., Bermudez, J. M., \& Lara-Lledo, M. (2015). The Effect of Active Packaging on Minimizing Food Losses: Life Cycle Assessment (LCA) of Essential Oil Component-enabled Packaging for Fresh Beef. Packaging Technology and Science, 28, 761-774.

\section{Appendix A. Derivation of Diffusion equation parameters}

Parameter values indicated in Table1 1 were obtained by combining the values presented in different scientific contributions. In this regard, for polypropylene (PP) layer, diffusivities at two different temperatures $(T=296.15 \mathrm{~K}, T=$ $373.15 \mathrm{~K}$ ) are presented in Cerisuelo et al. (2012) and Krepker et al. (2018), respectively: $D_{P P}(296.15 \mathrm{~K})=3.00 \times 10^{-15}, D_{P P}(373.15 \mathrm{~K})=9.42 \times 10^{-13}$ $\mathrm{m}^{2} \mathrm{~s}^{-1}$. Using Eq. (6), we obtain

$$
\begin{aligned}
& D_{P P}(296.15)=3.00 \times 10^{-15}=D_{P P}\left(T_{r e f}\right) \exp \left(-\frac{E_{A, P P}}{R}\left(\frac{1}{296.15}-\frac{1}{T_{r e f}}\right)\right) \\
& D_{P P}(373.15)=9.42 \times 10^{-13}=D_{P P}\left(T_{r e f}\right) \exp \left(-\frac{E_{A, P P}}{R}\left(\frac{1}{373.15}-\frac{1}{T_{r e f}}\right)\right)
\end{aligned}
$$

which, by dividing both equations, can be expressed as:

$$
\frac{3.00 \times 10^{-15}}{9.42 \times 10^{-13}}=\exp \left(-\frac{E_{A, P P}}{R}\left(\frac{1}{296.15}-\frac{1}{373.15}\right)\right)
$$

Taking into account that $R=8.314 \mathrm{~J} \mathrm{~mol}^{-1} \mathrm{~K}^{-1}$, we obtain $E_{A, P P}=1.27 \times 10^{5}$ $\mathrm{J} \mathrm{mol}^{-1}$.

On the other hand, reference temperature in Table 1 is $T_{r e f}=293.15 \mathrm{~K}$ so that:

$$
3.00 \times 10^{-15}=D_{P P}(293.15) \exp \left(-\frac{1.27 \times 10^{5}}{8.134}\left(\frac{1}{296.15}-\frac{1}{293.15}\right)\right)
$$

therefore, $D_{P P}\left(T_{r e f}\right)=D_{P P}(293.15)=1.77 \times 10^{-15} \mathrm{~m}^{2} \mathrm{~s}^{-1}$. 
घ For high-density polyethylene (HDPE) layer we used the values in Peltzer et al. (2009), i.e. $D_{H D P E}(298.15 \mathrm{~K})=8.13 \times 10^{-17} \mathrm{~m}^{2} \mathrm{~s}^{-1}$; and $D_{P P}(313.15 \mathrm{~K})=$ $5.01 \times 10^{-15} \mathrm{~m}^{2} \mathrm{~s}^{-1}$. Following the same procedure as in the case of PP layer, we firstly obtained the activation energy value, $E_{A, H D P E}=2.14 \times 10^{5} \mathrm{~J} \mathrm{~mol}^{-1}$ and secondly we used such value to obtain the diffusivity at the reference temperature, i.e. $D_{H D P E}\left(T_{r e f}\right)=D_{H D P E}(293.15)=1.80 \times 10^{-17} \mathrm{~m}^{2} \mathrm{~s}^{-1}$.

Finally, Rupika (2010) presented the values of carvacrol diffusivity in lowdensity polyethylene (LDPE) at three different temperatures: $D_{L D P E}(293.15 \mathrm{~K})=$ $8.10 \times 10^{-14} ; D_{L D P E}(288.15 \mathrm{~K})=3.80 \times 10^{-14} ;$ and $D_{L D P E}(283.15 \mathrm{~K})=1.90 \times 10^{-14}$ $\mathrm{m}^{2} \mathrm{~s}^{-1}$. In order to obtain the activation energy, logarithms are applied to the diffusivity equation so that:

$$
\log \left(D_{L D P E}(T)\right)=\log \left(D_{L D P E}\left(T_{r e f}\right)\right)-\frac{E_{A, L D P E}}{R}\left(\frac{1}{T}-\frac{1}{T_{r e f}}\right)
$$

This corresponds to a line equation with slope $-\frac{E_{A, L D P E}}{R}$. Activation energy can be, therefore, computed using linear regression: $E_{A, L D P E}=1.01 \times 10^{5}$ $\mathrm{J} \mathrm{mol}^{-1}$. 